\title{
Effect of drug properties on the release from CAP microspheres prepared by a solvent evaporation method
}

\author{
J. P. S. SILVA and J. P. M. FERREIRA* \\ Escola Superior de Biotecnologia - Universidade Católica Portuguesa, \\ Rua Dr. António Bernardino de Almeida, 4200 Porto, Portugal
}

\begin{abstract}
Drugs with different water-solubility and molecular weights were microencapsulated in cellulose acetate phthalate, using an emulsion-solvent evaporation technique with a continuous oil-phase. The mean size of the particles was approximately $600 \mu \mathrm{m}$, and they were non-porous. The capacity of the microspheres to retain the drugs was evaluated by in vitro release studies in acidic medium. For low molecular weight compounds the release rates increased with solubility: for thiamin hydrochloride and phenacetin, a highly and a poorly soluble compound respectively, the percentages released at $60 \mathrm{~min}$ were 90 and 10\%. Drugs with molecular weights above approximately 700 Da were retained in the microspheres. The above dependence on solubility was corroborated by release studies in ethanol, and by modelling the release of phenacetin in acidic media. Microspheres with a different polymer matrix, Eudragit ${ }^{\circledR}$ RS PO, were also prepared by a similar technique, and these particles prolonged the release of thiamin for over $6 \mathrm{~h}$, under simulated GI conditions.
\end{abstract}

Keywords: Microncapsulation, emulsion-solvent evaporation, drug properties, oral drug delivery.

\section{In trod uction}

A multitude of compounds have been incorporated in microcapsules and microspheres by several different techniques, in order to stabilize them, convert them into powders, to mask undesirable taste, or to provide modified release properties. Multiparticulate systems have gained great interest in oral drug delivery, as they show several advantages over single-unit dosage forms, such as lower variability in the GI transit times, better drug dispersion, and the possibility of mixing particles with different release properties (Follonier and Doelker 1992, Florence and Jani 1994). Microencapsulation of highly water-soluble drugs is a challenging task, both regarding the preparation technique, and in attaining particles with the desired release properties (Huang and Ghebre-Sellassie 1989). In fact, systems with such compounds are less common than with low watersolubility ones, as a great number of the pharmaceuticals belongs to this latter group. To avoid premature leaching in storage solutions, and to enable slower release in the GI tract, highly soluble drugs are of ten bound to ion-exchange resin particles, prior to coating with a polymer film, or they are incorporated into osmotic devices, among other systems (Bodmeir and Paeratakul 1994).

* To whom correspondence should be addressed. 
Regarding the coating technique, methods based on phase-separation are quite attractive, due to their simplicity and modest requirements in equipment. Variations of these methods have been used to encapsulate a highly water-soluble drug, pseudoephedrine $\mathrm{HCl}$, with different polymers (Huang and Ghebre-Sellassie 1989, Alex and Bodmeier 1990, Bodmeier et al. 1991, Manekar et al. 1992). These studies focus mainly on the development of emulsion techniques that improve drug entrapment efficiency.

This article analyses the effects of the drug solubility and molecular weight on the release properties of cellulose acetate phthalate (CAP) microparticles, prepared by an emulsion-solvent evaporation technique. For a highly water-soluble compound, thiamin hydrochloride, a comparison is carried out with microspheres of an insoluble acrylic resin. Results obtained with this and other model drugs, and using different release media, permitted the establishment of some heuristic principles for this type of preparation.

\section{Materials and methods}

\section{Materials}

Cellulose acetate phthalate (Schutz \&Co., Germany), Eudragit ${ }^{\circledR}$ RS PO(Rohm Pharma, Germany), aspirin (Rhône-Poulenc, France), thiamin hydrochloride (BASF, Germany), erythromycin, and phenacetin (Sigma, USA), magnesium stearate (Merck, Germany), Span 80 (Fluka, Switzerland), ethanol (Aga, Portugal), chloroform, ether, acetone, and paraffin (Vaz Pereira, Portugal) were used.

\section{Preparation of CAP microspheres}

The microspheres were prepared by a new solvent evaporation method, that has contributions from the methods reported by Beyger and Nairn (1986), and by Manekar et al. (1992).

Drug powder was previously passed through a $0.2 \mathrm{~mm}$ aperture sieve. CAP was dissolved in acetone at $10 \%(\mathrm{w} / \mathrm{v})$. Liquid paraffin $(100 \mathrm{ml})$ with $1 \%(\mathrm{w} / \mathrm{v})$ of Span 80 was placed in a $400 \mathrm{ml}$ beaker, and agitated at $400 \mathrm{tpm}$ with a 3-bladed propeller stirrer (diameter $5 \mathrm{~cm}$ ), linked to a stirring motor (Tecmatic SD2). Drug $(1 \mathrm{~g})$ was dispersed/dissolved in $20 \mathrm{ml}$ of the polymer solution. This mixture was then poured into the paraffin, and evaporation of the solvent proceeded for $2 \mathrm{~h}$ at 25 $30^{\circ} \mathrm{C}$. The microspheres were collected in a Buchener filter, washed with $50 \mathrm{ml}$ of ether, and allowed to dry at room temperature for $24 \mathrm{~h}$.

\section{Preparation of Eudragit $R S^{\circledR} P O$ microspheres}

A method similar to the one above was used, which corresponds also to a modification of the technique reported by Goto et al. (1986). Thiamin hydrochloride $(0.5 \mathrm{~g})$ was dispersed in a solution of polymer $(2.5 \mathrm{~g})$ and acetone $(30 \mathrm{ml})$, containing also magnesium stearate $(0.15 \mathrm{~g})$, and this mixture was poured into liquid paraffin $(100 \mathrm{ml})$. Microspheres were collected after evaporation of the solvent for $4 \mathrm{~h}$, and washed with $100 \mathrm{ml}$ cyclohexane.

For each drug-polymer system, at least two identical batches were prepared. 


\section{Particle sizing}

The distributions of particle size were determined with a set of sieves of apertures between 125-1250 $\mu \mathrm{m}$, and a vibratory shaker (Retsch AS 200).

\section{Release studies}

These studies were carried out under sink conditions in $0.1 \mathrm{~m} \mathrm{HCl}$ solution, and in ethanol, using sealed plastic tubes, agitated at $100 \mathrm{rpm}$, and with controlled temperature $\left(37^{\circ} \mathrm{C}\right.$ for $0.1 \mathrm{M} \mathrm{HCl}$, and $20^{\circ} \mathrm{C}$ for alcohol). Samples of media were taken at different times for analysis of drug content. All assays were done in duplicate.

\section{Drug concentrations}

Thiamin- $\mathrm{HCl}(\mathrm{Ti})$, aspirin (As), and phenacetin $(\mathrm{Ph})$ in 0.1 м $\mathrm{HCl}$ solution were quantified by UV spectrophotometry at 273,265 , and $245 \mathrm{~nm}$, respectively. $\mathrm{Ti}$ and As in alcohol were analysed similarly, at 273 and $226 \mathrm{~nm}$. Erythromycin (Er) was analysed by a modified version of the anthrone method reported by Alemany and Font (1983). This method was developed originally for quantification of sugars, and it was adapted in this study for Er, with a calibration curve at $483.5 \mathrm{~nm}$.

\section{Drug solubilities}

Values were taken from literature, or determined by dissolving saturating quantities of the drug in media at controlled temperature, for $24 \mathrm{~h}$, followed by filtration and quantification as above.

\section{Modelling of the release}

Drug release data were fitted to both the matrix model (Higuchi 1963) and to the first-order kinetic model (Benita and Donbrow 1982). The Higuchi model is described by the expression

$$
M_{t} / M_{\infty}=k t^{1 / 2}
$$

where $M_{t} / M_{\infty}$ is the fraction of the total drug released by time $t$, and $k$ is a constant. This equation is valid only for the initial release phase, for spheres when $M_{t} / M_{\infty}<0.15$ (Peppas and Peppas 1994).

For the first-order model, the equation is

$$
M_{t} / M_{\infty}=1-e^{-k t}
$$

Fittings to these equations were carried out by non-linear regressions with the least squares method, and using the computer software KaleidaGraph ${ }^{\mathrm{TM}}$ 3.0.1.

\section{Results and discussion}

\section{Drug properties and dissolution rates}

Absorption of a drug contained in a pharmaceutical oral form is preceded by its release and dissolution in the GI fluids. Thus knowledge of both the drug solubility and its dissolution rate are relevant. This latter property is particularly 
Table 1. Some physicochemical properties of the drugs.

\begin{tabular}{cccc}
\hline & & \multicolumn{2}{c}{ Solubility $(\mathrm{g} / \mathrm{L})$} \\
\cline { 3 - 4 } Drug & $\begin{array}{c}\text { Molecular } \\
\text { weight }\end{array}$ & 0.1 м HCl & Ethanol \\
\hline $\mathrm{Ti}$ & 337 & 700 & 3.2 \\
$\mathrm{As}$ & 180 & 4 & $200^{*}$ \\
$\mathrm{Ph}$ & 179 & 1 & $67^{*}$ \\
$\mathrm{Er}$ & 734 & 86 & nd \\
\hline
\end{tabular}

nd not determined.

*Solubility in ethyl alcohol 95\%.

Table 2. Dissolution rates of non-encapsulated drugs in 0.1 м $\mathrm{HCl}$ solution and in ethanol.

\begin{tabular}{cccc}
\hline & & \multicolumn{2}{c}{ Dissolution time } \\
\cline { 3 - 4 } Drug & Solvent & $30 \mathrm{~min}$ & $120 \mathrm{~min}$ \\
\hline $\mathrm{Ti}$ & $0.1 \mathrm{~m} \mathrm{HCl}$ & $100 \%$ & $100 \%$ \\
$\mathrm{As}$ & $0.1 \mathrm{~m} \mathrm{HCl}$ & $85 \% \%^{*}$ & $98 \% \%^{*}$ \\
$\mathrm{Ph}$ & $0.1 \mathrm{~m} \mathrm{HCl}$ & nd & $94 \%$ \\
$\mathrm{Ti}$ & Ethanol & $59 \%$ & $91 \%$ \\
\hline
\end{tabular}

nd not determined.

* According to Nokhodchi and Faird (1992)

important for compounds with low solubility. The solubilities in $0.1 \mathrm{~m} \mathrm{HCl}$ solution for the model compounds used in this study range from the highly soluble for $\mathrm{Ti}$, to the practically insoluble for $\mathrm{Ph}$ (table 1). In alcohol, $\mathrm{Ti}$ has low solubility, while As is very soluble (table 1), i.e. an inverse situation to the aqueous acidic medium. Er was also included in this work, in order to have a model compound with higher molecular weight than the others (table 1).

Dissolution rates of non-encapsulated drug powders were estimated under conditions similar to the release studies from the microspheres, and the results are presented in table 2. Ti dissolves immediately in $0.1 \mathrm{~m} \mathrm{HCl}$ medium. For As and $\mathrm{Ph}$, the processes are rather slower; nevertheless dissolutions are practically complete in $2 \mathrm{~h}$. In alcohol, Ti dissolution also takes approximately $2 \mathrm{~h}$.

\section{Physical characterization of CAP microspheres}

Table 3 represents the distribution of particle size for several batches of CAPdrug microspheres. In all cases, more than $80 \%$ (by weight) of the particles were within the range $250-1000 \mu \mathrm{m}$, with more than $50 \%$ in the range $500-710 \mu \mathrm{m}$ (exception for Ti). The mean particle diameter was approximately $600 \mu \mathrm{m}$, for all batches.

Microspheres containing $\mathrm{Ti}$ were also subjected to pore size analysis by mercury porosimetry (PoreSizer 9320, Micromeritics). The analysis revealed the absence of pores above the detection limit of the technique, which is around $6 \mathrm{~nm}$ (data not shown). 
Table 3. Distributions of particle size of CAP-drug microspheres.

\begin{tabular}{crrrrr}
\hline \multirow{2}{*}{$\begin{array}{c}\text { Interval } \\
\text { dimensions }\end{array}$} & \multicolumn{5}{c}{ Weight percentage (\%) } \\
\cline { 2 - 6 } & $\mathrm{Ti}$ & As I & As II & Ph I & Ph II \\
\hline $1250-1000 \mu \mathrm{m}$ & 17 & 1 & $>1$ & 3 & 1 \\
$1000-710 \mu \mathrm{m}$ & 27 & 7 & 14 & 32 & 9 \\
$710-500 \mu \mathrm{m}$ & 30 & 64 & 74 & 55 & 40 \\
$500-250 \mu \mathrm{m}$ & 25 & 28 & 10 & 10 & $>1$ \\
$250-125 \mu \mathrm{m}$ & 1 & $>1$ & $>1$ & $>1$ & \\
\hline
\end{tabular}

\section{Release studies}

In vitro release studies for CAP microparticles were carried out in simulated gastric juice $(0.1 \mathrm{~m} \mathrm{HCl})$, and in ethanol. CAP is insoluble in these two media. Eudragit $^{\circledR} \mathrm{RS}$ PO particles were assayed in $0.1 \mathrm{~m} \mathrm{HCl}$ solution, in which this polymer is also insoluble.

Figure 1 represents the release profiles in $0.1 \mathrm{~m} \mathrm{HCl}$ of different CAP-drug microspheres. Release of Ti is very rapid, with $80 \%$ of the total released in less than $30 \mathrm{~min}$. At $1 \mathrm{~h}$, over $90 \%$ Ti was in solution, but microspheres with As and $\mathrm{Ph}$ released approximately 50 and $10 \%$, respectively. Considering the values in table 1 , these compounds show a dependence between increasing drug solubility in $0.1 \mathrm{~m}$ $\mathrm{HCl}$ solution and shorter release time.

To corroborate this relation, release studies were carried out in a different medium that would provide altered relative solubilities of the drugs. Ethanol was selected, in which As is approximately 20 times more soluble than $\mathrm{Ti}$ (table 1). Release of these two drugs from CAP microspheres are depicted in figure 2. In this case, As release was completed in $20 \mathrm{~min}$, while Ti release was extremely slow, with only $7 \%$ released after $7 \mathrm{~h}$. These results support the above hypothesis.

The dissolution studies of the non-encapsulated drugs in both solvents indicate that dissolution per se is unlikely to be the limiting step.

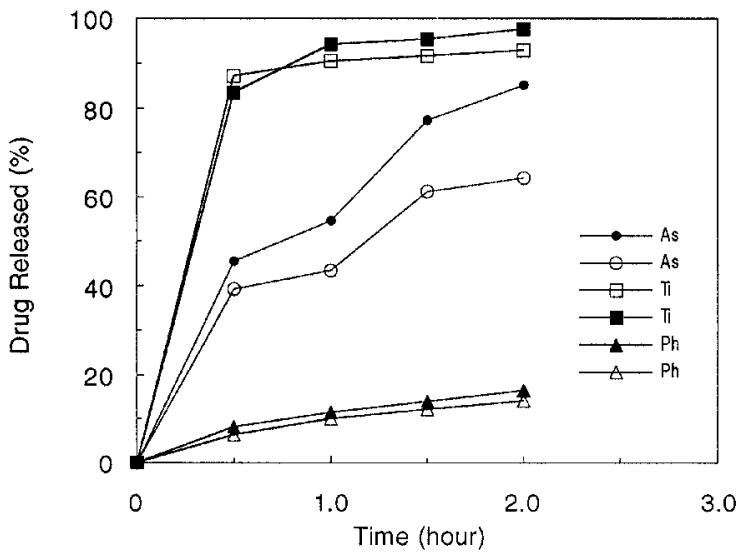

Figure 1. Drug release in $0.1 \mathrm{~m} \mathrm{HCl}$ solution for duplicate batches of CAP-drug microspheres: squares- $\mathrm{Ti}$; circles-As; triangles- $\mathrm{Ph}$ 


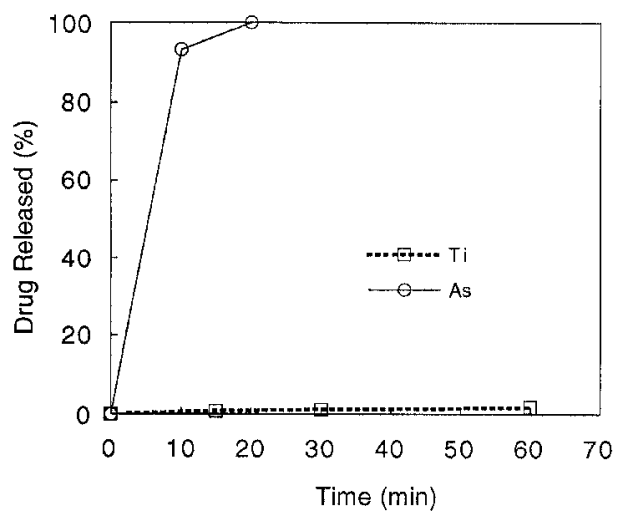

Figure 2. Drug release in ethanol from microspheres: squares-Ti; circles-As

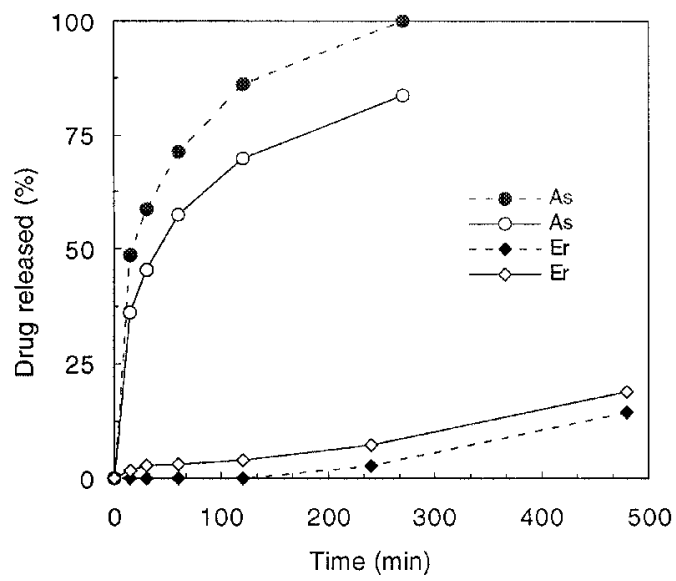

Figure 3. Drug release in $0.1 \mathrm{~m} \mathrm{HCl}$ solution for duplicate batches of CAP-drug microspheres: circles-As; lozenges-Er

The other drug physical property examined in this study was molecular weight. Release results of As (MW 180) and Er (MW 734) from CAP particles in $0.1 \mathrm{M}$ $\mathrm{HCl}$ solution are shown in figure 3. The release of Er was extremely slow, extending for over 4 days (not shown). At $2 \mathrm{~h}, \mathrm{Er}$ in solution was below detection, while $75 \%$ of the As had already been released. It must be noted that $\mathrm{Er}$ is approximately 20 times more soluble in this media than As. Thus, the differences from the previous results must be related to the molecular size of the compounds. Namely, the hydrodynamic diameter of Er must reach comparable magnitude to the interchain spaces in the CAP matrix. This hypothesis was also corroborated by one other preparation of CAP microspheres entrapping Coomassie brilliant blue (molecular weight 854); this compound is soluble in alcohol, but it was released from the particles to this medium at similar rates as Er in acid solution. Finally, the mercury porosimetry analysis (see above) also supports the observations of the release experiments. 
In order to develop particles that would possibly retain low molecular weight and highly soluble compounds, microspheres Eudragit ${ }^{\circledR}$ RS PO were prepared. This polymer forms films that are insoluble and with low permeabilities to aqueous media, and is used in many modified release oral forms. In this case, the in vitro release conditions were closer to the GI ones, with the medium exchanged at $2 \mathrm{~h}$ from hydrochloric acid to a $\mathrm{pH} 6.8$ buffer. As shown in figure 4, release of Ti from those microspheres was prolonged for over $6 \mathrm{~h}$. Also, during the first $4 \mathrm{~h}$, the release kinetics was close to zero-order, and it was not influenced by the exchange of the medium.

\section{Modelling of the release}

Drug release from microparticles have been described by the matrix model, or by the first-order kinetics equation (Benita 1984), among other models. Data of initial release (up to $17 \%$ ) obtained with the CAP-Ph microspheres in $0.1 \mathrm{~m} \mathrm{HCl}$ were fitted to both equations (1) and (2), using non-linear regressions. The release curve showed an excellent fitting to the matrix model, with correlation coefficients $\left(r^{2}\right)$ above 0.99 . The first order model was also tested with data from As and $\mathrm{Er}$ microspheres, but it provided very poor fittings.

The agreement of the release of $\mathrm{Ph}$, a poorly soluble drug in $0.1 \mathrm{M} \mathrm{HCl}$, with the matrix model supports the hypothesis of drug diffusion, rather than dissolution, being the limiting step in the release. The slow release must then result from a weak concentration gradient, due to the low saturation concentration $\left(C_{S}\right)$ of the drug.

\section{Conclusion s}

Development of gastric resistant microparticles containing low molecular weight and highly soluble compounds is a challenging issue. Thiamine $\mathrm{HCl}$ / Eudragit L microcapsules were prepared by Aly and Megwa (1989). The vitamin

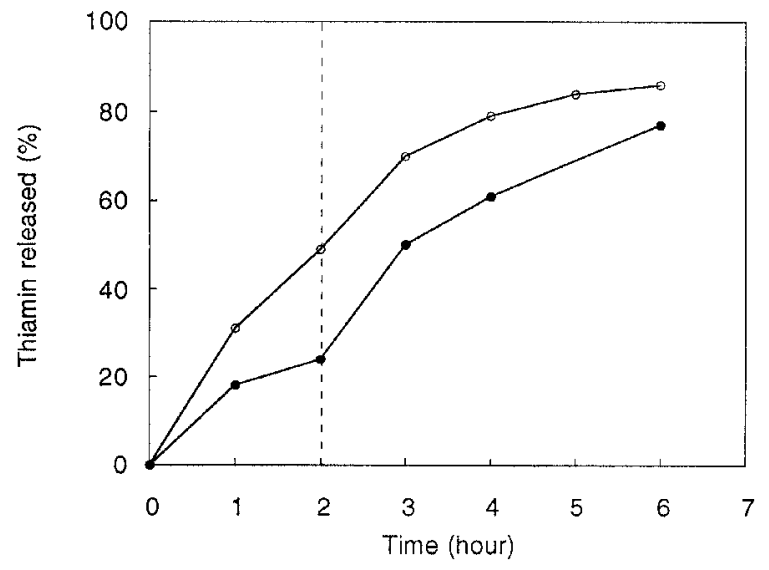

Figure 4. Drug release in $0.1 \mathrm{~m} \mathrm{HCl}$ solution (first $2 \mathrm{~h}$ ) and phosphate buffer, $\mathrm{pH} 6.8$ (after $2 \mathrm{~h}$ ) for duplicate batches of Eudragit ${ }^{\mathbb{B}} \mathrm{RS}$ PO-thiamin microspheres. 
was completely released in approximately $0.5 \mathrm{~h}$, in both alkaline and acidic medium. Kozlova et al. (1977) also reported that microcapsules of methyl cellulose, ethyl cellulose, or CAP, all released 90\% thyamin or ascorbic acid in less than $30 \mathrm{~min}$. Huang and Ghebre-Sellassie (1989) prepared microspheres of diphenhydramine $\mathrm{HCl}$ in ethylcellulose, using a water-in-oil emulsion. Drug and polymer were dissolved in alcohol, and the continuous phase was a mixture of light mineral oil:heptane (2:1). Drug release in distilled water were quite fast, except when a plasticizer, such as triethyl citrate, was included in the alcoholic solution. In these cases, $50 \%$ drug release was observed in approximately $2.5 \mathrm{~h}$. The same drug was encapsulated in ethylcellulose, poly(methyl methacrylate), and cellulose acetate butyrate by different oil-in-water emulsion procedures (Bodmeier et al. 1991); in $\mathrm{pH} 7.4$ buffer, these particles presented $t_{50}$ values between $2-4 \mathrm{~h}$. These results are in agreement with the ones in this report for the Eudragit microspheres (figure 4). Microparticles prepared by methods other than phase-separation ones generally show similar dependency of release behaviour on drug solubility. For instance, Ghebre-Sellassie et al. (1988) compared pellets containing diphenhydramine $\mathrm{HCl}$ or theophylline, a compound with low water-solubility. After $4 \mathrm{~h}$ in water, the first and the second group of pellets had released 90 and $15 \%$ of their drug content, respectively. Although some sophisticated alternative forms have been engineered to control the release of the highly soluble drugs, more in-depth and systematized analyses of the influence of the physicochemical properties are still needed.

In this study, CAP microspheres incorporating compounds with quite different solubilities were prepared by an emulsion/solvent evaporation method. This technique was shown to be simple, fast and reproducible. Highly soluble, low molecular weight drugs were quickly released from the CAP particles in acidic media. For less soluble compounds, the releases were retarded. Free drug dissolution tests and modelling studies suggested that these slower releases are likely to be diffusion-controlled rather than dissolution-limited. Also, compounds with molecular weight above $\approx 700 \mathrm{Da}$ did not exhibit this dependency on solubility, being retained in the polymer matrix.

Microspheres of the acrylic polymer Eudragit ${ }^{\circledR}$ RS PO, prepared by a technique similar to the CAP ones, provided prolonged release of a low molecular weight, highly soluble drug, and for a time adequate for oral administration.

\section{References}

Alemany, M., and Font, S., 1983, Determinación del contenido de materiales glucidicos en produtos naturels in Práticas de Bioquímica (Madrid: Alhambra) pp. 80-81.

Alex, R., and Bodmeier, R., 1990, Encapsulation of water-soluble drugs by a modified solvent evaporation method. I. Effect of process and formulation variables on drug entrapment. Journal of Microencapsulation, 7, 347-355.

Aly, S. A. S., and Megwa, S. A., 1989, In-vitro/in-vivo release of thyamine hydrochloride from microcapsules acrylic resin. Die Pharmazeutische Industrie, 51, 1163-1167.

Benita, S., 1984, Kinetic model identification of drug release from microcapsules using the nonlinear regression search procedure. Applied Biochemistry and Biotechnology, 10, 225-258.

Benita, S., and Donbrow, M., 1982, Release kinetics of sparingly soluble drugs from ethyl cellulose-walled microcapsules: theophylline microcapsules. Journal of Pharmacy and Pharmacology, 34, 77-82. 
Beyger, J. W., and Nairn, J. G., 1986, Some factors affecting the microncapsulation of pharmaceuticals with cellulose acetate phthalate. Journal of Pharmaceutical Science, 75, 573-578.

Bodmeier, R., and Paeratakul, I., 1994, Biopharmaceutical aspects of multiparticulates. In Multiparticulate Oral Drug Delivery, edited by I. Ghebre-Sellassie (New York, Basel and Hong-Kong: Marcel Dekker, Inc.), pp. 143-155.

Bodmeier, R., Chen, H., Tyle, P., and Jarosz, P., 1991, Pseudoephedrine HCl microspheres formulated into an oral suspension dosage form. Journal of Controlled Release, 15, 65-77.

Florence, A. T., and Jani, P. U., 1994, Novel oral drug formulations - their potential in modulating adverse effects. Drug Safety, 19, 233-266.

Follonier, N., and Doelker, E., 1992, Biopharmaceutical comparison of oral multiple-unit and single-unit sustained-release dosage forms. S. T.P. Pharma Sciences, 2, 141-158.

Ghebre-Sellassie, I., Iyer, U., Kubert, D., and Fawzi, M. B., 1988, Characterization of a new water-based coating for modified-release preparations. Pharmaceutical Technology, 12, 96-106.

Goto, S., Kawata, M., Nakamura, M., Maekawa, K., and Aoyama, T., 1986, Eudragit RS and $\mathrm{RL}$ (acrylic resins) microcapsules as $\mathrm{pH}$ insensitive and sustained release preparations of ketoprofen. Journal of Microencapsulation, 3, 293-304.

Higuchi, T., 1963, Mechanism of sustained-action medication. Theoretical analysis of rate of release of solid drugs dispersed in solid matrices. Journal of Pharmaceutical Science, 52, 1145-1149.

Huang H., and Ghebre-Sellassie, I., 1989, Preparation of microspheres of water-soluble pharmaceuticals. Journal of Microencapsulation, 6, 219-225.

Kozlova, I. V., Dontsova, G. I., Chlenov, V. A., Lebedenko, V. Y., and Gryadunova, G. P., 1977, Investigation of the process of microencapsulation of water soluble vitamins, Farmatsiya (Moscow), 26, 37-39.

Manekar, N. C. Puranik, P. K., and Joshi, S. B., 1992, Microencapsulation of propranolol hydrochloride by solvent evaporation solvent. Journal of Microencapsulation, 9, 6366.

Noкнорснi, A., and Farid, D., 1992, Effect of various factors on microencapsulation of acetyl salicylic acid by a non-solvent addition method. S.T.P. Pharma Sciences, 2, 279-283.

Peppas, N. A., and Peppas, L., 1994, Water diffusion and sorption in amorphous macromolecular systems and foods. Journal of Food Engineering, 22, 181-210. 